\title{
A PRODUÇÃO DO CONHECIMENTO NO CAMPO DA EDUCAÇÃO PROFISSIONAL NO REGIME DE ACUMULAÇÃO FLEXÍVEL
}

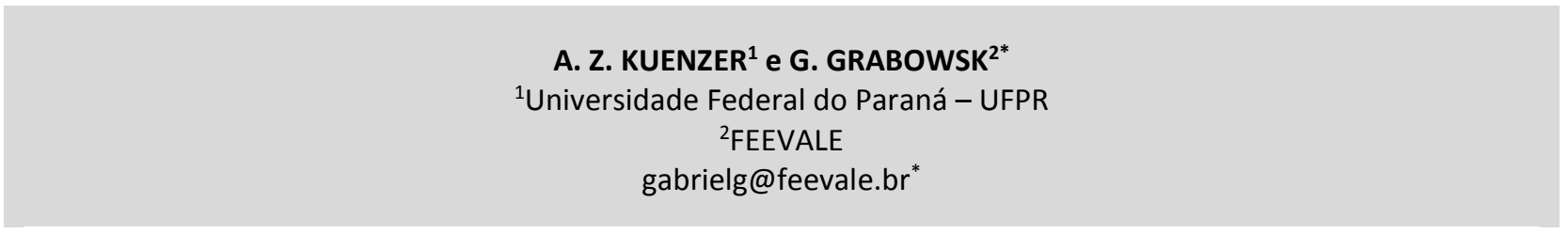 \\ Artigo submetido em agosto/2016 e aceito em setembro/2016 \\ DOI: $10.15628 /$ holos.2016.4983
}

\section{RESUMO}

Esse texto parte do seguinte questionamento: existe um campo epistemológico próprio da educação profissional? Entendendo campo epistemológico como o estudo crítico dos princípios, das hipóteses e dos resultados das diversas ciências, destinado a determinar sua origem lógica, há que compreender a educação profissional, não como um campo em si, mas como parte do campo da ciência da educação, que se constitui por categorias de método e por categorias de conteúdo. Para tanto,
sSerão analisadas algumas das categorias de conteúdo constituintes do campo epistemológico da educação, que assumem especificidades ao se tratar de educação profissional. A análise evidenciaou que a flexibilização do trabalho, categoria central a definir o campo epistemológico da educação em geral e da educação profissional no regime de acumulação flexível, representa o seu esgotamento, destruindo os poucos direitos que a classe trabalhadora conquistou ao longo de suas lutas.

PALAVRAS-CHAVE: Produção do conhecimento, Educação profissional, Acumulação flexível.

\section{KNOWLEDGE PRODUCTION IN THE FIELD OF VOCATIONAL TECHNICAL EDUCATION UNDER A FLEXIBLE SPECIALIZATION REGIME}

\begin{abstract}
This text derives from the following question: is there an epistemological field only for vocational technical education? Once the epistemological field is a critical study of principles, hypothesis and the results from various sciences aimed at determing its own logical origin, there must be a comprehension on vocational technical education, not only as a field of knowledge in itself, but as a component of the educational science field that is constituted of method and content categories.
\end{abstract}

Thus, some categories of contents constituting of the epistemological field will be analyzed. They assume some specificities about vocational technical education. The analysis demonstrated that the work flexibilization, central category defining the espitemological field of education and vocational technical education under a flexible specialization regime, represents its collapse. Therefore it destroys the few rights the working class has conquered through the years with their fights.

KEYWORDS: Knowledge production, Vocational Technical Education, Flexible Specialization 


\section{INTRODUÇÃO}

Ao iniciar este texto, uma primeira reflexão se faz necessária: existe um campo epistemológico próprio da educação profissional? Entendendo campo epistemológico como o estudo crítico dos princípios, das hipóteses e dos resultados das diversas ciências, destinado a determinar sua origem lógica, há que compreender a educação profissional, não como um campo em si, mas como parte do campo da ciência da educação, que se constitui por categorias de método e por categorias de conteúdo. E se, do ponto de vista do método, compreendermos o processo de produção do conhecimento a partir da ação humana sobre a realidade, não há como compreender e sistematizar as categorias de conteúdo senão a partir das suas relações com a realidade que as determinaram, e ao mesmo tempo são determinadas por elas.

Uma segunda reflexão que se faz necessária diz respeito ao fato de que existem, pelo menos três posturas epistemológicas que definem as formas de interpretação da realidade, resultantes das três grandes correntes do pensamento ocidental: o positivismo (o conhecimento está inscrito no objeto investigado, devendo a verdade ser buscada na natureza), a fenomenologia ( o objeto é apreendido pela intencionalidade do sujeito, que o reduz à sua essência) e a dialética marxista ( conhecer é alcançar a dinâmica histórica do real, do objeto em todos os seus aspectos em seu contínuo movimento, em sua permanente relação com o sujeito). Dependendo, portanto, da opção metodológica do pesquisador, o método, as categorias, e por consequência, os resultados da investigação, serão distintos.

Assim, ao analisar as categorias que constituem a educação profissional, há que compreendê-las como parte do campo epistemológico da educação, derivando, a partir de categorias que são gerais, as que lhe são específicas, e a partir de uma postura epistemológica definida; no caso deste artigo, a dialética marxista.

A partir dessa opção epistemológica, entende-se que essas categorias só podem ser compreendidas na materialidade das relações de produção nas quais se inserem: as relações entre capital e trabalho, contraditórias no modo de produção capitalista. Em consequência, não há campos categoriais paralelos, senão categorias que, geradas no bojo do modo de produção capitalista, assumem diferentes sentidos, dependendo do ponto de vista adotado: do capital ou do trabalho, em decorrência do que serão contraditórios.

Para dar clareza à análise, necessário se faz elucidar que a autora trabalha, com apoio no método da economia política, com as categorias em duas dimensões: as categorias de método e as categorias de conteúdo. As categorias de método são as que definem as formas de relacionamento entre o pesquisador (sujeito) e o objeto da investigação; na dialética marxista, essas categorias são a práxis, a totalidade, a contradição e a mediação.

As categorias de conteúdo são os fios condutores da análise, que expressam, no particular, as explicações mais gerais; são recortes particulares, definidos a partir do objeto e das finalidades da investigação, a partir dos quais é possível apreender as relações, os conceitos, as formas de organização. São as categorias de conteúdo que servem de critério de seleção e organização da teoria e dos fatos a serem investigados, fornecendo à pesquisa o princípio de sistematização que Ihe conferirá sentido, cientificidade, rigor, relevância (KUENZER, 1998). 
A partir dessas considerações, serão analisadas algumas das categorias de conteúdo constituintes do campo epistemológico da educação, que assumem especificidades ao se tratar de educação profissional. Dada a necessidade de recorte em face das dimensões desse texto, a análise contemplará o atual regime de acumulação: o da produção flexível.

Para a análise que será levada a efeito, parte-se do pressuposto que cada sociedade, em cada momento de desenvolvimento das forças produtivas, formula projetos pedagógicos que atendam às demandas de formação de subjetividades para atender às necessidades da divisão social e técnica que caracterizam o modo de produção dominante (GRAMSCl, 1978). Esses projetos pedagógicos orientam as relações educativas em seu conjunto, sejam as amplamente pedagógicas, que ocorrem no bojo das relações sociais, sejam as especificamente pedagógicas, que ocorrem nos processos escolares, intencionais e sistematizados.

A categoria princípio educativo do trabalho, que supõe a compreensão dos processos de formação humana, e portanto, superestruturais, a partir das bases materiais de produção da existência (infraestruturais), constitui, decorrente que é da centralidade da categoria trabalho, uma das categorias de conteúdo centrais que constitui o campo epistemológico da educação a partir da dialética marxista. O princípio educativo define os processos de formação dos intelectuais que irão desempenhar as diferentes funções no sistema social e produtivo, e sua apreensão só será possível a partir do estudo das bases materiais que lhe dão origem. É a partir dele que se desdobram as categorias que irão compor o campo específico da educação profissional, e que permitem apreender os diferentes projetos de formação em um dado regime de acumulação, com vistas à acumulação do capital.

Na sociedade capitalista, o princípio educativo expressa as contradições entre capital e trabalho, que originam projetos educativos em permanente disputa, cuja objetivação, sempre parcial, depende da correlação de forças decorrente das relações sociais e produtivas em cada regime de acumulação.

A seguir, a partir da categoria princípio educativo, serão elencadas algumas categorias que constituem especificamente o campo da educação profissional, apontando, sem a pretensão de esgotar a análise, o significado que tomam a partir dos projetos educativos do capital e do trabalho.

\section{A DUALIDADE ESTRUTURAL NEGADA PELA FLEXIBILIZAÇÃo}

Entre as categorias que permitem compreender a educação no modo de produção capitalista está a dualidade estrutural; contudo, é a partir do ensino médio, e em especial na educação profissional, que essa categoria apresenta maior poder explicativo.

No regime de acumulação rígida, em que havia clara definição entre as funções operacionais, técnicas, de gestão e de desenvolvimento de ciência e tecnologia típicas das formas tayloristas/fordistas de organizar o trabalho, as trajetórias educativas eram bem definidas e diferenciadas, de modo a atender às necessidades de disciplinamento dos trabalhadores e dirigentes. Em outro texto, denominei essa modalidade de dualidade estrutural assumida, porquanto claramente explicitada. Dadas as novas formas de organização e gestão do trabalho, a dualidade estrutural assume nova forma, que denominei de dualidade negada, uma vez que, justificada pela flexibilização trazida pela nova base técnica da microeletrônica, supõe a sua superação. (KUENZER, 2007) 
No regime de acumulação flexível, do ponto de vista do capital, a substituição da base rígida pela base flexível, através da mediação da microeletrônica, traz um novo discurso sobre a dualidade, que aponta, supostamente, para a sua superação.

Este discurso se justifica apontando os sinais de esgotamento do fordismo e do keinesianismo na contenção das contradições inerentes ao capitalismo, resultantes da rigidez nos investimentos, dos mercados, da alocação e dos contratos de trabalho, das posições dos sindicatos, das relações entre estado, capital e trabalho expressas nas políticas públicas, das formas de organizar e gerir o processo de trabalho e das tecnologias de base física.

A superação da acumulação rígida pela acumulação flexível traz a necessidade de novas formas de disciplinamento da força de trabalho, que contemplem o desenvolvimento de subjetividades que atendam às exigências da produção e da vida social, caracterizadas pela flexibilidade, para que acompanhem as mudanças tecnológicas decorrentes da dinamicidade da produção científico-tecnológica contemporânea, ao invés de profissionais rígidos, que repetem procedimentos memorizados ou recriados através da experiência.

Para que esta formação flexível seja possível, torna-se necessário substituir a formação especializada adquirida em cursos profissionalizantes voltados para ocupações parciais, pela formação geral adquirida através de escolarização ampliada, que abranja no mínimo a educação básica, a ser disponibilizada para todos os trabalhadores.

O novo discurso do capital sobre a educação aponta para a necessidade da formação de profissionais flexíveis; se o trabalhador transitará ao longo de sua trajetória laboral por inúmeras ocupações e oportunidades de educação profissional, não há razão para investir em formação profissional especializada; a integração entre as trajetórias de escolaridade e laboral será o elo de integração entre teoria e prática, resgatando-se, desta forma, a unidade rompida pela clássica forma de divisão técnica do trabalho, que atribuía a uns o trabalho operacional, simplificado, e a outros o trabalho intelectual, complexo.

Assim, a distinção entre as modalidades propedêutica e profissional restaria superada pela oferta de educação geral para todos, assegurada mesmo nos cursos profissionalizantes, como determina a nova LDB. A formação profissional dar-se-á a partir da formação geral, que deverá ter caráter mais abrangente do que especializado, a ser complementada ao longo das práticas laborais. Como a proposta é substituir a estabilidade pela dinamicidade, à educação cabe desenvolver competências que permitam aprender ao longo da vida, uma das categorias chave na pedagogia da acumulação flexível.

Do ponto de vista do trabalho, contudo, as pesquisas já mostram que a expansão da educação geral para a classe trabalhadora se deu, de modo geral, pela oferta de cursos precarizados, revestidos de caráter certificatório, cuja qualidade, que em muito se distancia dos cursos disponibilizados pela rede privada à burguesia e à pequena burguesia, não favorecem inclusão menos subordinada no mundo do trabalho (KUENZER, 2006 e 2007). Em resumo, quando o capital disponibiliza para a classe trabalhadora, uma modalidade que já correspondeu, em outro regime de acumulação, ao seu projeto de dominação, o faz pela via precarizada. Assim, como o ensino médio de educação geral, caro à burguesia no regime de acumulação rígida, já não atende ao seu projeto no regime de educação flexível, ele passa a ser generalizado para a classe trabalhadora; para a classe dominante, no novo regime, é o conhecimento em ciência e tecnologia que passa a ser o diferencial. Em outro texto, denominei essa nova manifestação da dualidade 
estrutural de "dualidade invertida", uma vez que há estudos que evidenciam que, para os jovens mais pobres, a expansão da educação geral não ampliou as oportunidades de inserção no mundo do trabalho (RIBEIRO e NEDER, 2009; KUENZER, 2010; SUHR, 2014).

Do ponto de vista das novas formas de disciplinamento demandadas pelo capital, elas objetivam a conformação de subjetividades flexíveis que se ajustem aos resultados do acelerado processo de destruição e reconstrução de habilidades, da terceirização, do crescimento dos níveis de desemprego estrutural, da redução dos salários, da desmobilização sindical. (HARVEY, 1992, p.141)

Em resumo, essas novas formas de disciplinamento buscam a submissão, por parte da classe trabalhadora, aos processos flexíveis caracterizados pela intensificação e pela precarização, a configurar o consumo cada vez mais predatório e desumano da força de trabalho.

Assim, revela-se a dimensão ideológica do discurso do regime de acumulação flexível sobre a educação, uma vez que aprofundam-se as diferenças de classe, e consequentemente, aprofunda-se a dualidade estrutural, expressa na crescente polarização das competências.

Analisada a dimensão ideológica da dualidade negada no regime de acumulação flexível, necessário se faz apontar que, por contradição, também há positividades nessa proposta para a classe trabalhadora, no que diz respeito à educação profissional. Dentre elas, há que destacar a ampliação da oferta de educação básica para a classe trabalhadora, que passou a ser demandada pelo próprio capital a partir dos anos 90 , em face da crescente utilização das novas tecnologias na vida social e no processo produtivo.

A partir do momento em que a produção e o consumo na acumulação flexível passam a demandar uma relação com o conhecimento sistematizado, ou seja, de natureza teórica, mediada pelo domínio de competências cognitivas complexas, com destaque para as competências comunicativas e para o domínio da lógica formal, há um processo crescente de intelectualização das competências, contrariamente ao que ocorria no taylorismo/fordismo, cuja concepção de conhecimento fundava-se na dimensão tácita: resolver situações pouco complexas através de ações aprendidas através da experiência.

Como a nova base técnica demanda solução de problemas gerados por sistemas tecnológicos complexos, ampliam-se as demandas por escolarização, o que gerou a possibilidade de ampliação da oferta de educação em todos os níveis e modalidades, com destaque para a expansão, e de modo interiorizado, da rede dos Institutos Federais de Educação e para a criação de novas Universidades Federais regionalizadas.

Do mesmo modo, a defesa da expansão da escolaridade para a classe trabalhadora, feita pelo próprio capital, abriu espaço para a defesa, pela sociedade civil, de diretrizes curriculares mais democráticas junto ao MEC e ao CNE; de programas de formação de professores; de programas de investimento em pesquisa; de propostas de ampliação do investimento; e da oferta de programas de educação média e profissional no âmbito dos Planos Nacionais de Educação.

\section{EDUCAÇÃO GERAL PARA A FORMAÇÃO DO “TRABALHADOR MULTITAREFA"}

A formação de subjetividades flexíveis, tanto do ponto de vista cognitivo quanto ético se dá, predominantemente pela mediação da educação geral; é através dela, disponibilizada de forma 
diferenciada por origem de classe, que os que vivem do trabalho adquirem conhecimentos genéricos que Ihes permitirão exercer, e aceitar, múltiplas tarefas no mercado flexibilizado. Ser multitarefa, neste caso, implica em exercer trabalhos simplificados, repetitivos, fragmentados, para o que é suficiente um rápido treinamento, a partir de algum domínio de educação geral, o que não implica necessariamente no acesso à educação básica completa.

Neste sentido, a educação geral, assegurada pelos níveis que compõem a educação básica, tem como finalidade dar acesso aos conhecimentos fundamentais e às competências cognitivas que permitam a integração à vida social e produtiva em uma organização social com forte perfil científico-tecnológico, um dos pilares a sustentar o capitalismo tardio, na perspectiva do disciplinamento do produtor/consumidor; e por isto a burguesia não só a disponibiliza, mas a defende, para os que vivem do trabalho.

Ser flexível, para uma expressiva parcela de trabalhadores, significa adaptar-se ao movimento de um mercado que inclui/exclui, segundo as necessidades do regime de acumulação. A competência, nos pontos desqualificados das cadeias produtivas, resume-se ao conhecimento tácito, demandado pelo trabalho concreto. Não há, para estes trabalhadores que atuam nos setores precarizados, demandas relativas ao desenvolvimento da competência de trabalhar intelectualmente em atividades de natureza científico-tecnológica, em virtude do que não se justifica formação avançada.

Neste sentido, as políticas de educação, ao negar aos que vivem do trabalho, a possibilidade de acesso à formação tecnológica, em nome de uma educação genérica, respondem às demandas da acumulação.

Para os que exercerão atividades complexas na ponta qualificada das cadeias produtivas, a educação básica é rito de passagem para a educação científico-tecnológica e sócio-histórica de alto nível. Nestes casos, a flexibilidade, atributo geralmente exercitado internamente às firmas, advém da capacidade de trabalhar intelectualmente e atuar praticamente, para usar a expressão gramsciana, (GRAMSCl, 1978), estabelecendo-se uma maior integração entre concepção e atuação. Ou, como afirma Antunes (2002, p. 42/43), a nova fase do capital retransfere o saber fazer para o trabalho, apropriando-se de sua dimensão intelectual, procurando envolver mais intensamente a subjetividade operária. Ao mesmo tempo, transfere parte do saber intelectual para as máquinas informatizadas que se tornam mais inteligentes, reproduzindo parte das atividades a elas transferidas pelo saber intelectual.

Ser multitarefa, para os trabalhadores que atuam nos pontos mais qualificados das cadeias produtivas, significa a capacidade de adaptar-se a múltiplas situações complexas e diferenciadas, que demandam o desenvolvimento de competências cognitivas mais sofisticadas que permitam a solução de problemas com rapidez, originalidade e confiabilidade. Para tanto, há que assegurar formação avançada, que articule as dimensões geral e específica..

A segunda categoria, portanto, que configura a dualidade na acumulação flexível, é a distribuição desigual e diferenciada de educação que, ao contrário do que ocorria no taylorismo/fordismo, valoriza a educação básica para os que vivem do trabalho, como condição para a formação flexível, e educação específica, de natureza científico-tecnológica e sócio-histórica para os que vão exercer o trabalho intelectual, de modo a assegurar que a posse do que é estratégico, nesse caso o conhecimento que permite inovação, permaneça com o capital. 
A estratégia através da qual o conhecimento é disponibilizado/negado segundo as necessidades desiguais e diferenciadas dos processos de trabalho integrados é o que temos chamado de inclusão excludente na ponta da escola. Ao invés da explícita negação das oportunidades de acesso à educação continuada e de qualidade, há uma aparente disponibilização das oportunidades educacionais, através de múltiplas modalidades e diferentes naturezas, que se caracterizam por seu caráter desigual e na maioria das vezes meramente certificatório, que não asseguram domínio de conhecimentos necessários ao desenvolvimento de competências cognitivas complexas vinculadas à autonomia intelectual, ética e estética.

Conclui-se, desta rápida exposição, que a relativização da qualificação com foco na ocupação permite a formação de um maior contingente de trabalhadores com mais educação, se possível básica completa, e até superior, o que viabilizará maior flexibilidade em seu uso combinado ao longo das cadeias produtivas. Desta forma, caracteriza-se menor dependência do capital em relação ao trabalho qualificado, que, pelo uso flexível, fica mais vulnerável.

Já o conhecimento científico tecnológico, integrado à cultura e ao trabalho, por seu caráter estratégico para a competitividade através da inovação, tem sua distribuição mais controlada, e embora também seja disponibilizado de forma diferenciada para atender aos arranjos flexíveis, tem caráter mais elitizado.

Enfim, a relativização da qualificação pela banalização das competências, ao tempo que liberta o capital das competências específicas, Ihe permite maior liberalidade quanto à oferta de educação mais ampliada, o que, inclusive, passa a defender...desde, é claro, que mantenha privada a propriedade do conhecimento estratégico à acumulação, qual seja, o conhecimento científicotecnológico e sócio-histórico de ponta, reservado aos intelectuais seus prepostos.

\section{A INTELECTUALIZAÇÃO DAS COMPETÊNCIAS: A RELAÇÃO ENTRE CONHECI- MENTO TÁCITO E CONHECIMENTO CIENTÍFICO}

O processo de intelectualização das competências no regime de acumulação flexível, decorrente da base microeletrônica, reconfigura a relação entre conhecimento tácito e conhecimento científico, trazendo novos elementos à constituição teórica desta categoria.

No regime de acumulação rígida, a competência, predominantemente psicofísica e fragmentada, advinda antes da experiência do que da relação com o conhecimento sistematizado, tinha natureza predominantemente tácita, para a maioria das ocupações. Este conhecimento, subjetivado, constitui-se de formas inconscientes, não sistematizadas, não transferíveis e geralmente não reconhecidas, através das quais os trabalhadores, mesmo desqualificados, resolvem os problemas derivados das prescrições de trabalho, a partir do que têm amplo poder de intervenção. (JONES e WOOD, 1984)

Esse conhecimento, contudo, não desaparece com a implantação de novas tecnologias, em particular com as de base microeletrônica, mas muda de qualidade, passando a exigir maior aporte de conhecimentos científicos que não podem ser obtidos somente através da prática, senão através de cursos sistematizados.

Contudo, se a implantação de novas tecnologias de base microeletrônica não prescinde do conhecimento tácito dos trabalhadores, demanda relação permanente e sistematizada com o 
conhecimento teórico, através do domínio das categorias do trabalho intelectual, o que leva à necessidade de formação sistematizada.

Esta conclusão, ao tempo que valoriza o conhecimento tácito, contraditoriamente põe os trabalhadores em maior dependência de conhecimentos científicos a serem obtidos através de processos formativos escolares e não escolares, o que pode levar ao aprofundamento da dualidade. Assim é que os trabalhadores com dificuldades de requalificação intelectualizada em decorrência da precarização cultural derivada da origem de classe, tendem ou à exclusão ou à inclusão nos setores mais precarizados nos arranjos flexíveis de força de trabalho.

Vista desta forma, a relação entre conhecimento tácito e conhecimento científico na base microeletrônica não é de oposição, e sim de articulação dialética, posto que são categorias que se integram nos processos de trabalho flexibilizados, nos quais a prevalência do tácito ou do científico responde à especificidade do trabalho a ser realizado por uma força de trabalho de qualificações diferenciadas que se articulam para atender às necessidades das cadeias produtivas.

Ou, como afirma Antunes, ontologicamente prisioneira do solo material estruturado pelo capital, o saber científico e o saber laborativo mesclam-se mais diretamente no mundo contemporâneo; contudo a transferência das capacidades intelectuais para a maquinaria, como afirma autor, acentua a transformação do trabalho vivo em trabalho morto, mas não pode eliminálo. $(2005$, p. 41$)$

Llory reforça este argumento com dados de pesquisa sobre os acidentes industriais, concluindo que é no e pelo trabalho cotidiano e graças à atividade e ao savoir-faire dos trabalhadores em todos os níveis, que a maioria dos acidentes latentes não se tornam acidentes ativos (2001, p. 21a 26). Quando os controles automatizados falham, ou quando o planejador do sistema de controle não previu proteções para um dado evento, o controle dos acidentes depende do conhecimento dos trabalhadores, ou seja, do trabalho vivo.

A base microeletrônica, portanto, a medida em que traz à discussão a concepção de competência enquanto práxis, apontando para a relação dialética que se estabelece entre conhecimento tácito e conhecimento científico, e valorizando o trabalho vivo, aponta a necessidade de uma formação mais complexa da força de trabalho, mais multifuncional, que será explorada de modo mais intenso e sofisticado (ANTUNES, 2005, p.41). É importante lembrar, contudo, que esta demanda de formação mais intelectualizada, contrariando o discurso do capital, não se distribui por toda a cadeia produtiva, estando presente apenas nos setores tecnologicamente mais desenvolvidos. Para os trabalhadores que estão presos a tarefas desqualificadas ou pouco complexas tecnologicamente, o conhecimento tácito permanece fundamental.

De qualquer modo, estas conclusões trazem ao debate o caráter mediador da ação educativa, que articula, no plano do pensamento e através do trabalho intelectual, teoria e prática, de modo a permitir a compreensão e sistematização do conhecimento tácito, e sua transformação em conhecimento científico. Justifica-se, deste modo, o resgate das ações educativas sistematizadas, escolares e não escolares, para os que vivem do trabalho, na contramão das práticas elitistas do regime de acumulação flexível, em que pese o discurso seja o da efetiva democratização. 


\section{ARRANJOS FLEXÍVEIS DE COMPETÊNCIAS DIFERENCIADAS}

Diferentemente do que ocorria no taylorismo/fordismo, onde as competências eram desenvolvidas com foco em ocupações previamente definidas e relativamente estáveis, a integração produtiva se alimenta do consumo flexível de competências diferenciadas que se articulam ao longo das cadeias produtivas. Estas combinações não seguem modelos préestabelecidos, sendo definidas e redefinidas segundo as estratégias de contratação e subcontratação que são mobilizadas tendo em vista atender, de forma competitiva, as necessidades do mercado, e assim assegurar as maiores margens de lucro possíveis, que, no processo de internacionalização, tendem a ser estreitadas. Em decorrência, só podem ser apreendidas através da análise da dinâmica da integração produtiva enquanto totalidade complexa em permanente processo de construção e reconstrução, a partir da lógica da acumulação flexível.

Consequentemente, os arranjos flexíveis, em substituição à polarização taylorista/fordista de competências, não podem ser compreendidos como mera oposição, rígida e formal, entre os que têm formação científico-tecnológica avançada, e por isso se incluem, e a grande massa de trabalhadores precariamente escolarizados, cuja força de trabalho é consumida predatoriamente em trabalhos desqualificados, ou é excluída. São combinações que ora incluem, ora excluem trabalhadores com diferentes qualificações, de modo a constituir corpos coletivos de trabalho dinâmicos, através de uma rede que integra diferentes formas de subcontratação e trabalho temporário, que, ao combinar diferentes estratégias de extração de mais-valia, asseguram a realização da lógica da mercantil.

Se há combinação entre trabalhos desiguais e diferenciados ao longo das cadeias produtivas, há demandas diferenciadas, e desiguais, de qualificação dos trabalhadores; contudo, os arranjos são definidos pelo consumo da força de trabalho necessário, e não a partir da qualificação. $O$ foco não é a qualificação em si, mas como ela se situa em dada cadeia produtiva, com o que ela se relativiza; a priori, não há como afirmar que certo trabalhador é ou não qualificado, uma vez que isto se define a partir de sua inclusão na cadeia; ou seja, a dimensão de relação social da qualificação se superalativiza na acumulação flexível, que avança na centralização do trabalho abstrato.

Assim é que trabalhadores qualificados que estão incluídos em um determinado arranjo, poderão não estar em outros, ou os que são qualificados para certos elos da cadeia não o serão necessariamente para outros; estar incluído a partir de uma dada qualificação não assegura que não esteja excluído em outros momentos, e vice-versa, dependendo das necessidades do sistema produtivo. O que determina a inclusão na cadeia, portanto, não é a presença ou a ausência de qualificação, mas as demandas do processo produtivo que combinam diferentes necessidades de ocupação da força de trabalho a partir da tarefa necessária à realização da mercadoria.

Daí o caráter "flexível" da força de trabalho; importa menos a qualificação prévia do que a adaptabilidade, que inclui tanto as competências anteriormente desenvolvidas, cognitivas, práticas ou comportamentais, quanto a competência para aprender e para submeter-se ao novo, o que supõe subjetividades disciplinadas que lidem adequadamente com a dinamicidade, com a instabilidade, com a fluidez. 
A afirmação, portanto, da necessidade de elevação dos níveis de conhecimento e da capacidade de trabalhar intelectualmente, professada no discurso sobre a educação na acumulação flexível, mostra seu caráter concreto: a necessidade de ter disponível para consumo nas cadeias produtivas, força de trabalho com qualificações desiguais e diferenciadas, que combinadas em células, equipes, ou mesmo linhas, atendendo a diferentes formas de contratação, subcontratação e outros acordos precários, assegurem os níveis desejados de produtividade, através de processos de extração de mais valia que combinam as dimensões relativa e absoluta.

Ao contrário do discurso da negação da dualidade, a análise das formas de consumo do trabalho nas cadeias produtivas evidencia o aprofundamento da distribuição desigual, onde para alguns, dependendo de onde e por quanto tempo estejam integrados nas cadeias produtivas, se reserva o direito de exercer, e sempre provisoriamente, o trabalho intelectual integrado às atividades práticas, a partir de extensa e qualificada trajetória de escolarização; o mesmo não ocorre com a maioria dos trabalhadores, que desenvolvem conhecimentos tácitos pouco sofisticados, em atividades laborais de natureza simples e desqualificada.

\section{CONCLUSÃO: A FLEXIBILIZAÇÃO MATERIALIZA O CONSUMO PREDATÓRIO DA FORÇA DE TRABALHO}

A análise realizada neste texto evidencia que a flexibilização do trabalho, categoria central a definir o campo epistemológico da educação em geral e da educação profissional no regime de acumulação flexível, longe de conduzir ao avanço no processo civilizatório do próprio capital, representa o seu esgotamento, destruindo os poucos direitos que a classe trabalhadora conquistou ao longo de suas lutas. (FRIGOTTO, 2005, p. 69).

A essência da flexilibização é a a combinação ótima ( nunca máxima, pois esta compromete o custo final do produto) entre investimento em ciência e tecnologia e consumo de competências desiguais e diferenciadas ao longo das cadeias produtivas. A estratégia, portanto, é o aumento de produtividade através da integração dos sistemas de produção, e não da mera implantação da automação; esta, quando adotada, é definida a partir das necessidades da integração dos sistemas de produção.

É através da subcontratação organizada que sistemas mais antigos, como o trabalho domiciliar, familiar, artesanal e paternalista deixem de ser marginais e assumem um novo papel, passando a ser orgânicos, e portanto fundamentais ao processo de acumulação.

Ou seja, relações de trabalho que se supunham superadas através do processo civilizatório do capital, retornam como estratégias essenciais ao processo de acumulação, combinadas com relações mais contemporâneas mediadas pela ciência e pela tecnologia, através da flexibilização.

A compreensão, portanto, das categorias que regem a dualidade estrutural na acumulação flexível só pode se dar através da apreensão das combinações que se dão através da integração dos sistemas produtivos, o que exige uma análise mais ampliada que capte as relações ao longo das cadeias.

Estas categorias não se revelam completamente através de análises parciais que recortem partes do fenômeno; há que superar as oposições formais ou polarizações para apreender as categorias na totalidade em movimento, em processo de constituição. 
Ou, em síntese, se a flexilibilização e a integração são categorias de conteúdo essenciais para assegurar ganhos ao capital, para os trabalhadores elas assumem o significado de consumo predatório da força de trabalho.

\section{REFERÊNCIAS BIBLIOGRÁFICAS}

1. ANTUNES, R. Trabalho e superfluidade. In: SAVIANI, D.; SANFELICE, J.L.; LOMBARDI,J .C. (Org.).Capitalismo, trabalho e educação. 3. ed. Campinas: Autores Associados, 2005. p. 35 a 44.

2. FRIGOTTO, G. Estruturas e sujeitos: os fundamentos da relação entre trabalho e educação. In: Saviani, D.; Sanfelice, J.L.; Lombardi, J.C. (Org.). Capitalismo, trabalho e educação. 3. ed. Campinas: Autores Associados, 2005. p. 61-74.

3. GRAMSCI, A . Maquiavel, a política e o Estado moderno. Rio de Janeiro, Civilização, 1978.

4. HARVEY, D. A condição pós-moderna. 7. ed. São Paulo: Loyola, 1998. 349p

5. JONES e WOOD. Qualificações tácitas, divisão do trabalho e novas tecnologias. Sociologia dutravail. N. 4, 1984. (tradução livre)

6. KUENZER, A.Z. Desafios teórico metodológicos da relação trabalho-educação e o papel social da escola. In: Gaudêncio Frigotto. (Org.). Educação e Crise do trabalho: perspectivas de final de século. 1ed.Rio de Janeiro: Vozes, 1998, v. 1, p. 55-92.

7. KUENZER, A. Z. A educação profissional nos anos 2000: a dimensão subordinada das políticas de inclusão. Educação e Sociedade, v. 27, p. 877-910, 2006.

8. KUENZER, A. Z. Da dualidade assumida à dualidade negada; o discurso da flexibilização justifica a inclusão excludente.. Educação e Sociedade, v. 28, p. 1153-1178, 2007.

10. KUENZER, A. Z. O Ensino Médio no Plano Nacional de Educação 2011-2020. Educação \& Sociedade (Impresso), v. 112, p. 851-874, 2010.

11. LLORI, M. Acidentes industriais: o custo do silêncio. Rio de Janeiro: Multiação, 2001.

12. RIBEIRO, R., NEDER, H. Juventude(s): desocupação, pobreza e escolaridade. Nova Economia. Belo Horizonte, 19(31), p. 475-506, set/dez, 2009.

13. SUHR, I. R. F. Ensino médio de Educação geral: possibilidade de ampliação laboral da classe que vive do trabalho?. 2010. Tese de Doutorado em Educação - Universidade Federal do Paraná. 